\title{
Influence of different leavening agents on technological and nutritional characteristics of whole grain breads obtained from ancient and modern flour varieties
}

\author{
Manuel Venturi ${ }^{1} \cdot$ Viola Galli ${ }^{2}$ - Niccolò Pini ${ }^{2} \cdot$ Simona Guerrini ${ }^{1} \cdot$ Costanza Sodi ${ }^{2} \cdot$ Lisa Granchi $^{2}$
}

Received: 11 February 2021 / Revised: 22 March 2021 / Accepted: 27 March 2021 / Published online: 12 April 2021

(c) The Author(s) 2021

\begin{abstract}
The aim of the work was to assess the influence of the leavening agent on several technological, chemical, and nutritional characteristics of breads prepared with whole soft wheat (Triticum aestivum L.) flours. As leavening agents in bread-making, baker's yeast, biga, and sourdough were utilized. Two ancient varieties, Andriolo and Verna, and a modern grain variety, Bologna, were used. Analysis of the obtained breads included the measurement of the phenols content, the antioxidant activity, the in vitro protein and total digestibility, the texture profile, the crumb grain characteristics and the microbial shelf-life test. The results of the principle component analysis of bread features indicated a clustering depending especially on the leavening agent rather than on the employed flour, particularly when sourdough was used. Protein digestibility, crumb grain characteristics, and shelf-life led to the main differences among the samples. Ancient wheat flour displayed similar features when the same leavening agent was applied. Particularly, the use of sourdough levelled the differences due to flour, leading to breads with similar technological and nutritional characteristics. The findings highlighted a marked effect of the leavening agent on bread final characteristics.
\end{abstract}

Keywords Leavening agent $\cdot$ Ancient wheat varieties $\cdot$ Whole wheat flours $\cdot$ Sourdough $\cdot$ Biga $\cdot$ Bread

Viola Galli

viola.galli@unifi.it

Manuel Venturi

manuel@foodmicroteam.it

Niccolò Pini

niccolo.pini@unifi.it

Simona Guerrini

simona@foodmicroteam.it

Costanza Sodi

ctn.sodi@gmail.com

Lisa Granchi

lisa.granchi@unifi.it

1 FoodMicroTeam S.R.L., Via di Santo Spirito n. 14, Florence, Italy

2 Department of Agriculture, Food, Environment and Forestry (DAGRI), University of Florence, Via San Bonaventura, 13, 50145 Florence, Italy

\section{Introduction}

Bread is a staple food in many diets worldwide. The type of flours and the leavening agent play a major role in determining its final quality. As regard to flours, whole grain flours show a general better nutritional quality, possessing high content of fibre, minerals, micronutrients, and bioactive compounds [1] compared to refined flours. In addition, they have been demonstrated to possess beneficial health effect, being protective against cancer, cardiovascular disease, diabetes, and obesity [2]. The main concern of their utilization regards the poor technological performances for bread-making, particularly due to the presence of the bran fraction respect to the refined flour that are made only from the endosperm of wheat. Among whole wheat flours, ancient grains such as Verna, Gentil rosso, Senatore Cappelli, and Andriolo, have gained interest in the recent years particularly for their enhanced nutritional characteristics [3, 4]. Ancient grains are generally defined as varieties that have not been subjected to breeding programs, thus remaining unchanged over the last hundred years, in contrast to the so-called modern wheat varieties that have been selected from the $1960 \mathrm{~s}$ 
onwards by genetic improvement procedures for better milling performances [3]. The term "ancient grains" is used in the literature for either old Triticum aestivum $\mathrm{L}$. varieties or wheat relatives such as emmer; in this paper, the definition used is the former. A recent article [5] highlights the multiple positive effects derived from ancient grains consumption such as a significant reduction in the risk of chronic diseases (e.g., cancer, cardiovascular disease) and a more favourable long-term weight management and increase in satiety. Regarding functional compounds, such as polyphenols (flavonoids, lignans, isoflavones), carotenoids, tocopherols and fiber, significant differences were found between the ancient and the modern wheat varieties, especially in terms of compounds variety rather than of quantity $[6,7]$. Bread-making with ancient wheat cultivars have been investigated in several works [8-10], but none of them assessed the influence of the leavening agent on the consequent production process and the characteristics of the obtained bread. Indeed, bread-making comprises several technologies that differ above all for the type of leavening agent that is reflected on the production process. Sourdough technology represents certainly the oldest one. Sourdough is defined as a mixture of flour and water containing a metabolically active microbiota composed by lactic acid bacteria (LAB), responsible for acidification, and yeasts, that mainly carry out the leavening of the dough [11]. Sourdough is kept active by continuous refreshments that select a stable and characteristic microbiota, which is well adapted to the specific recipe and manufacturing procedures. To simplify the bakery process, industries can replace or integrate sourdough with baker's yeast that consists of Saccharomyces cerevisiae cells. Baker's yeast can be added directly into the final dough (straight dough technology) or indirectly preparing an intermediate firm dough, known as biga, that is added to the final dough after 16-18 $\mathrm{h}$ of fermentation. Sourdough is usually recognized to improve the nutritional and organoleptic properties of the final products, especially thanks to the metabolic activity of LAB. However, it is considered a time-consuming procedure, difficult to standardize, compared to baker's yeast employment that reduces the time of work and allows an easier management. To date, few studies investigated the effect of different bakery technologies on the characteristics of breads made with whole grain ancient flours [12]. Therefore, the aim of this study was to assess, through an integrated approach, the impact of three breadmaking technologies (sourdough, straight dough, and biga) on several technological, chemical, and nutritional characteristics of breads obtained with three wheat whole flour varieties, two Tuscan ancient grains (cv Andriolo and cv Verna) and one modern variety (cv Bologna).

\section{Materials and methods}

\section{Raw materials}

Three Italian whole grains flour varieties, cultivated in Tuscany, were used in this study: two ancient wheat cultivar, Andriolo and Verna, and a modern cultivar, Bologna. Whole grain flours were provided by Azienda Agricola Mellini Mauro (Bibbiena, Arezzo, Italy). Flour from each cultivar was obtained by stone milling process. The whole grain milling was carried out without any sifting processes, thus all anatomical kernel components, including the endosperm, germ, and bran are present in the same relative proportions as in the intact kernel. Baker's yeast (Zeus Iba, Florence, Italy) and salt (Florence, Italy) were purchased in a local supermarket.

\section{Flour rheological analysis}

Rheological properties of flours were evaluated with a Chopin NG alveograph, assembled with an alveolink integrator-recorder (Chopin technologies, Villeneuve-La-Garenne, France). As defined in the standard protocol (ISO, 27971 International Standard, 2008), dough tenacity (P), dough extensibility (L), deformation energy (W), the curve configuration ratio $(\mathrm{P} / \mathrm{L})$, were evaluated.

\section{Bread-making}

The recipe for each prepared bread is reported in Table 1 . A type 1 (traditional) sourdough, containing the lactic acid bacteria species Fructilactobacillus sanfranciscensis, and two yeast species, Saccharomyces cerevisiae, and Kazachstania humilis was used. Before its addition in the final dough, sourdough (dough yield of 153) was backslopped $(25 \% \mathrm{w} / \mathrm{w})$ and left to ferment for $6 \mathrm{~h}$ in a proofing chamber
Table 1 Ingredients and percentage on total dough of each sample

\begin{tabular}{|c|c|c|c|c|c|c|}
\hline \multirow[t]{2}{*}{ Ingredients } & \multicolumn{2}{|c|}{ Baker's yeast dough } & \multicolumn{2}{|c|}{ Biga dough } & \multicolumn{2}{|l|}{ Sourdough dough } \\
\hline & $\mathrm{g}$ & $\%$ on dough & $\mathrm{g}$ & $\%$ on dough & $\mathrm{g}$ & $\%$ on dough \\
\hline Flour & 1280 & 64 & 975 & 48,75 & 975 & 48,75 \\
\hline Water & 700 & 35 & 525 & 26,25 & 525 & 26,25 \\
\hline Leavening agent & Baker's yeast 20 & 1 & Biga 500 & 25 & Sourdough 500 & 25 \\
\hline Total & 2000 & 100 & 2000 & 100 & 2000 & 100 \\
\hline
\end{tabular}


(Unipan; Alaska, Costa di Rovigo, Rovigo, Italy) at $30{ }^{\circ} \mathrm{C}$ and $88-90 \%$ relative humidity. Biga dough was prepared by adding baker's yeast $0.5 \%(\mathrm{w} / \mathrm{w})$, into a dough with dough yield of 153. The dough was mixed for $10 \mathrm{~min}$ in a twin arms mixer model RS12 (Bernardi, Cuneo, Italy) and left to ferment for $18 \mathrm{~h}$ in the proofing chamber at $30^{\circ} \mathrm{C}$ and $88-90 \%$ relative humidity before its utilization.

In Fig. 1, the flow sheet of each bread-making process is shown.

The ingredients were mixed for $10 \mathrm{~min}$ in the twin arms mixer model RS12. Each dough was divided in moulds of $100 \mathrm{~g}$ and placed in the proofing chamber at $30^{\circ} \mathrm{C}$ and $88-90 \%$ relative humidity for different times according to the production process (Fig. 1). Dough samples were taken at the beginning and at the end of the proofing time for microbiological and chemical analyses. Finally, doughs were baked at $180^{\circ} \mathrm{C}$ for $25 \mathrm{~min}$ in an oven (Rossella, Unox, Padua, Italy), with vapor injection during baking.

\section{Enumeration of cultivable bacteria and yeasts, and determination of $\mathrm{pH}$, total titratable acidity and volume increase}

Ten grams of the dough at the end of proofing time were transferred into $90 \mathrm{~mL}$ of sterile physiological solution and homogenized for $2 \mathrm{~min}$. After decimal dilutions, $100 \mu \mathrm{L}$ of these suspensions were plated for cell enumeration using MR3i medium [13] for the lactobacilli and MYPG for the yeasts using the pour plate method. Lactobacilli were counted after incubation for $48-72 \mathrm{~h}$ at $30^{\circ} \mathrm{C}$ under anaerobic conditions. Yeasts, plated on MYPG agar containing sodium propionate $(2 \mathrm{~g} / \mathrm{L})$, were counted after incubation for $48 \mathrm{~h}$ at $30^{\circ} \mathrm{C}$ under aerobic conditions. Plate counts were performed in duplicate. The $\mathrm{pH}$ values were determined by a $\mathrm{pH}$-meter (Metrohm Italiana Srl, Varese, Italy). The total titratable acidity (TTA) was measured by homogenizing $10 \mathrm{~g}$ of dough samples with $90 \mathrm{~mL}$ of distilled water for $3 \mathrm{~min}$. The TTA was expressed as a quantity $(\mathrm{mL})$ of $0.1 \mathrm{~mol} / \mathrm{L} \mathrm{NaOH}$ to reach a $\mathrm{pH}$ of 8.5 . To assess dough increase of volume, $100 \mathrm{~g}$ of each dough were placed in a graduated cylinder $(0.5 \mathrm{~L})$. The volume of the doughs (in $\mathrm{mL}$ ) was recorded immediately and after fermentation at $30^{\circ} \mathrm{C}$. The volume increase was calculated using the following
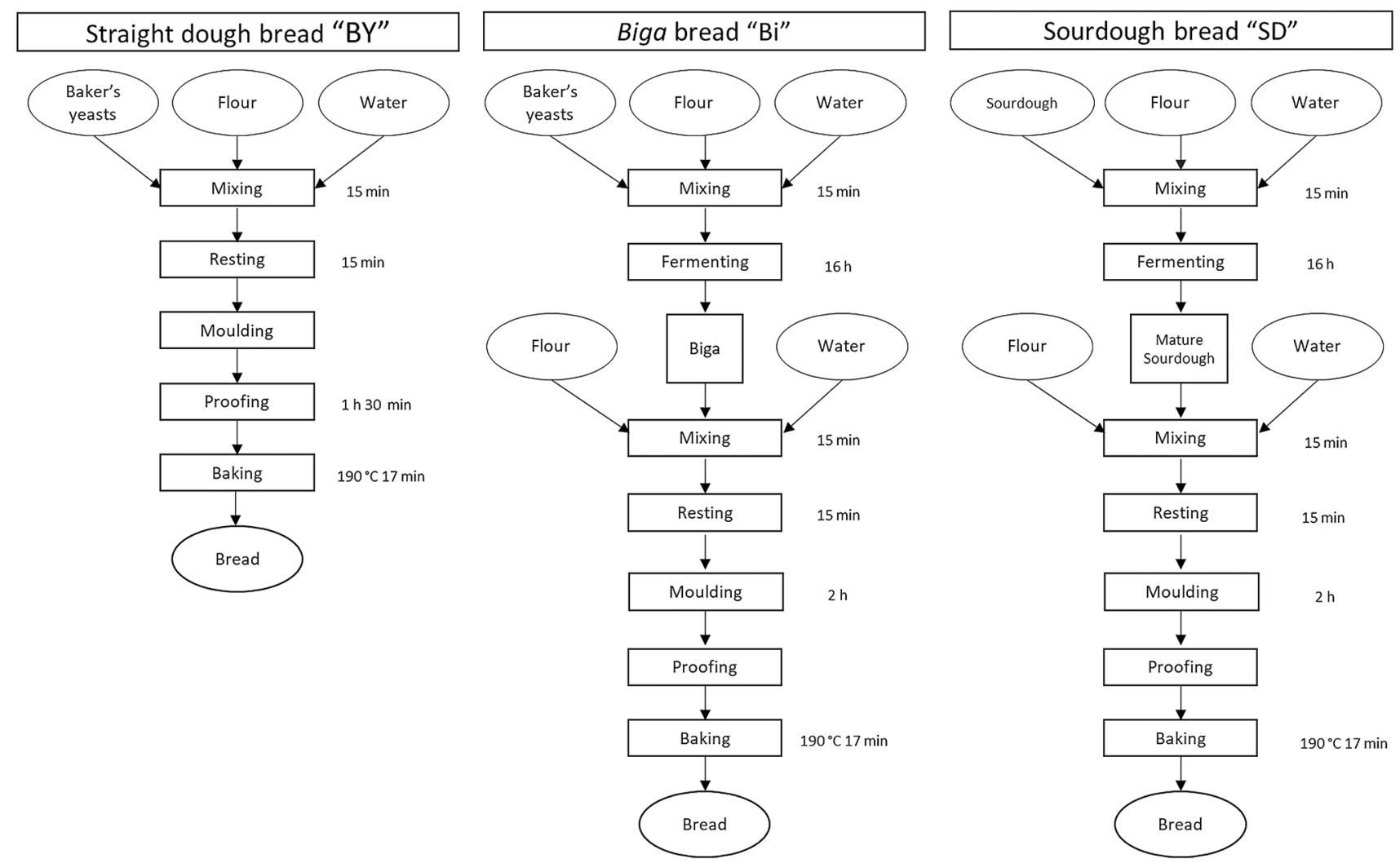

Fig. 1 Flow sheet of each bread-making process. $B Y$ dough leavened with only baker's yeast, $B i$ dough leavened with biga, $S D$ dough leavened with sourdough 
formula: $\frac{V_{f n}-V_{0}}{V_{0}} \times 100$, where $\mathrm{V}_{\text {fin }}$ was the volume after each different fermentation time and $\mathrm{V}_{0}$ was the initial volume [13].

\section{Bread analyses}

\section{Total phenols assay by Folin-Ciocalteau reagent}

For the measurement of the phenols content, samples were prepared as reported by Alvarez-Jubete et al. [14] with some modifications. Bread samples were dried for $24 \mathrm{~h}$ at $60{ }^{\circ} \mathrm{C}$ and ground and $1.25 \mathrm{~g}$ were added to $25 \mathrm{~mL}$ of methanol. Samples were vortexed and then left in horizontal shaking for $24 \mathrm{~h}$, then centrifuged for $10 \mathrm{~min}$ at $2000 \times \mathrm{g}$. The final extracts were obtained by filtering $10 \mathrm{~mL}$ of the supernatant through $0.22 \mu \mathrm{m}$ PTFE syringe filters (Whatman, Maidstone, UK) and were stored at $-20^{\circ} \mathrm{C}$ until analysis. The total phenolic content of methanolic bread extracts were evaluated using a modified version of the Folin-Ciocalteau assay as described by AlvarezJubete et al. [14]. The reaction mixture consisted of $100 \mu \mathrm{L}$ of methanolic grain extract or standard, $100 \mu \mathrm{L}$ of $\mathrm{MeOH}$, $100 \mu \mathrm{L}$ of Folin-Ciocalteau reagent and $700 \mu \mathrm{L}$ of $\mathrm{Na}_{2} \mathrm{CO}_{3}$. The samples were vortexed immediately and incubated in the dark for $20 \mathrm{~min}$ at room temperature. After incubation, all samples were centrifuged at $11,300 \times g$ for $3 \mathrm{~min}$. The absorbance of the supernatant was then measured at $735 \mathrm{~nm}$ using a spectrophotometer UV-1700 PharmaSpec (Shimadzu, Milton Keynes, UK). Gallic acid was used as a standard and a calibration curve was prepared with a range of concentrations from 10 to $200 \mathrm{mg} / \mathrm{L}$. The results are expressed in $\mathrm{mg}$ gallic acid equivalent per $100 \mathrm{~g}$ dry-weight basis (mg GAE/100 $\mathrm{g} \mathrm{dwb}$ ).

\section{Antioxidant activity by DPPH assay}

The free radical scavenging capacity of methanolic bread and flour extracts was determined using the stable 2,2-diphenyl1-picrylhydrazyl radical (DPPH). The scavenging effect was measured according to the method of Alvarez-Jubete et al. [14]. $500 \mu \mathrm{L}$ of extracts were added to $500 \mu \mathrm{L}$ of DPPH methanolic solution $(0.05 \mathrm{mg} / \mathrm{mL})$. After vortexing, the mixture was left for $40 \mathrm{~min}$ at room temperature, and the absorbance of the resulting solution was read at $517 \mathrm{~nm}$. The absorbance measured after 40 min was used for the calculation of the antioxidant capacity according to the following formula: containing $0.05 \mathrm{mg} / \mathrm{mL}$ of pepsin. After $60 \mathrm{~min}, 1.15 \mathrm{~mL}$ of $1 \mathrm{~mol} / \mathrm{L}$ boric acid, $0.5 \mathrm{~mol} / \mathrm{L} \mathrm{NaOH}$, adjusted to $\mathrm{pH} 6.8$ with $5 \mathrm{~mol} / \mathrm{L} \mathrm{HCl}$, and containing $0.25 \mathrm{mg} / \mathrm{mL}$ of pancreatin, was added. The resulting $\mathrm{pH}$ was 7.6. Both the reactions were performed at $37^{\circ} \mathrm{C}$ in a shaking water bath and stopped at different times $(0,30$ min of pepsin attack and 30,60, and 120 min of pancreatic digestion, coding the obtained samples PD30, PD60 and PD120, respectively) by addition of 1 volume of $20 \%(\mathrm{w} / \mathrm{v})$ trichloroacetic acid (TCA). After standing for $1 \mathrm{~h}$, the samples were centrifuged $(8000 \times \mathrm{g}$, $15 \mathrm{~min}$ at $5{ }^{\circ} \mathrm{C}$ ) and the pellet was analyzed for nitrogen content using the Elemental Analyser (CHN-Thermo Fisher Scientific) according to the Dumas combustion method. Total protein was obtained by multiplying the total nitrogen content by 5.70 . The in vitro total digestibility (IVTD) was calculated by gravimetric method (mg) after $120 \mathrm{~min}$ of pancreatic digestion using the following formula: $I V T D \%=\frac{W_{0}-W P D_{120}}{W_{0}} \times 100$, where $\mathrm{W}_{0}$ is the initial weight of freeze-dried samples and $\mathrm{WPD}_{120}$ is the weight of the sample after $120 \mathrm{~min}$ of pancreatic digestion.

\section{Texture profile analysis (TPA)}

Slices of the same thickness $(1 \mathrm{~cm})$ were obtained from each bread. The Texture Profile Analysis (TPA) of bread samples was carried out by two-bite compression using a Texture Analyzer (Stable Micro Systems, UK), equipped with a circular flat-plate probe (diameter: $30 \mathrm{~mm}$ ), according to the procedure described in Kim et al. [16]. Hardness (N), cohesiveness, and springiness $(\mathrm{mm})$ were measured.

\section{Crumb grain characteristics}

Image analysis was performed for slices from the internal part of each loaf (thickness- $1 \mathrm{~cm}$ ) which were scanned by a copy machine (Olivetti d-COPIA 4500 FMplus). The acquired images were processed using Image $J$ (http://rsb. info.nih.gov/ij/). The images were elaborated according to Demirkesen et al. [17]. Loaf height $(\mathrm{cm})$ was determined. Crumb grain was described by the following parameters: pore area, pore area fraction, and porosity (number of pores per $\mathrm{cm}^{2}$ ) values. In addition, pore size and pore area

DPPH radical scavenging activity $(\%)=\frac{(\text { blank absorbance-sample absorbance })}{\text { blank absorbance }} \times 100$

\section{In vitro protein and total digestibility}

In vitro protein digestion was performed according to Pasini et al. [15] with some modifications. $60 \mathrm{mg}$ of freeze-dried breads were suspended in $4 \mathrm{~mL}$ of $0.2 \mathrm{~mol} / \mathrm{L} \mathrm{HCl}(\mathrm{pH} 2.2)$ distribution were obtained according to five pre-selected categories based on pore equivalent diameter (eq.d.), in cm: $0.05<$ eq.d. $\leq 0.1$ (class 1 ), $0.1<$ eq.d. $\leq 0.2$ (class 2), $0.2<$ eq.d. $\leq 0.3$ (class 3 ), $0.3<$ eq.d. $\leq 0.5$ (class 4 ), eq.d. $>0.5$ (class 5 ). Equivalent diameter was calculated 
using the following formula: eq.d. $=2 \sqrt{A / \pi}$; where $A$ is pore area.

\section{Microbial shelf-life}

Bread microbial shelf-life was evaluated by a visual assessment of moulds on bread surface, monitored daily [18]. After cooling, breads were packaged in sterile polyethylene bags and stored at $25{ }^{\circ} \mathrm{C}-75 \% \mathrm{RH}$. The end of shelf-life was established when three out of ten breads showed mould colonies. The results are expressed in days.

\section{Statistical analysis}

The numerical results of microbial, chemical, and technological analyses are averages of two or three independent replicates. Data were analyzed by one-way or two-way analysis of variance (ANOVA) using GraphPAD Prism 6 (GraphPAD Software, San Diego, CA, USA).The means comparisons were determined by Tukey's test $(p<0.05)$. The principal component analysis (PCA) was carried out using STATISTICA 7 software.

\section{Results and discussion}

\section{Flour characterization}

The three flours employed in this study were characterized for several rheological parameters, related to baking potential, and for some chemical characteristics related to nutritional quality, summarized in Table 2.

As regard to alveograph parameters such as dough strength and tenacity, the two ancient varieties (Andriolo and Verna) exhibited similar values that resulted lower compared to those of Bologna variety. Similarly, the $\mathrm{W}$ values of the Andriolo and Verna flours were lower than Bologna flour (52 and $77 \times 10^{-4} \mathrm{~J}$, respectively) and below from the minimum values generally required by the bread-making industry $\left(150 \times 10^{-4} \mathrm{~J}\right)$. Indeed, it has been reported that old varieties display lower dough strength in comparison to the modern varieties [19]. Bologna flour showed better bread-making characteristics also in terms of $\mathrm{P}$ value (tenacity); whereas the low L index (extensibility) value led to an unbalanced $\mathrm{P} / \mathrm{L}$ index that is not included in the optimum range of 0.4-0.7. Andriolo is a variety with an unknown origin, probably a selection of the Terricchio variety, characterized by high rusticity and it is referred to as mountain wheat. Verna was obtained by Gasparini in 1953 from the cross between Est Mottin $72 \times$ Mont Calme 245 . This variety is suitable to mountainous areas and it can be described as very rustic, with exceptional resistance to cold and rust [20]. Flours associated to a specific region are more susceptible to seasonal variation [21], thus leading to a less standardized product, characterized by a broad variations of the rheological parameters [9]. In general, old varieties are considered weak flour and often processed as Italian Type 2 flour or as whole grain flour. Protein amount, similarly to rheological features, is strongly influenced by annual variability and cultivar characteristics. Our findings highlighted a lower protein content in the modern variety, compared to those of ancient grains. Nevertheless, dough strength and tenacity resulted lower in the latter. As reported by several authors [22, 23] the gluten content and quality, rather than protein content, is a predominant factor affecting dough technological quality, even though a direct relationship has not been demonstrated. Total phenolic content of flour methanolic extracts were higher in the two ancient wheat cultivar and led to a higher antioxidant capacity, hence improving their overall nutritional quality. Whole wheat flours are generally rich in phenolic acids, however their biosynthesis and accumulation strongly depends on both variety and environmental conditions $[24,25]$.

\section{Dough analysis}

For each bread-making process (straight dough with baker's yeast, biga dough, and sourdough) volume and yeast concentration of the doughs at the end of leavening time were determined. In the doughs prepared with sourdough, final lactic acid bacteria concentration, $\mathrm{pH}$, and Total Titratable

Table 2 Flour rheological and chemical characteristics

\begin{tabular}{lccccccc}
\hline Flour & $\mathrm{W} \times 10^{-4} \mathrm{~J}$ & $\mathrm{P}\left(\mathrm{mmH}_{2} \mathrm{O}\right)$ & $\mathrm{L}(\mathrm{mm})$ & $(\mathrm{P} / \mathrm{L})\left(\mathrm{mmH}_{2} \mathrm{Ox} \mathrm{mm} \mathrm{mm}^{-1}\right)$ & Protein $(\mathrm{g} / 100 \mathrm{~g}) \mathrm{i}$ & $\begin{array}{l}\text { Total phenolic } \\
\text { content }(\mathrm{mg} \\
\mathrm{GAE} / 100 \mathrm{~g})\end{array}$ & Antioxidant activity $(\%)$ \\
\hline cv Andriolo & $52 \pm 8^{\mathrm{a}}$ & $42 \pm 6^{\mathrm{a}}$ & $42 \pm 5^{\mathrm{b}}$ & $1.00 \pm 0.11^{\mathrm{a}}$ & $11.20 \pm 0.69^{\mathrm{b}}$ & $28 \pm 1.3^{\mathrm{b}}$ & $57.48 \pm 2.38^{\mathrm{b}}$ \\
cv Verna & $77 \pm 10^{\mathrm{a}}$ & $56 \pm 11^{\mathrm{a}}$ & $44 \pm 8^{\mathrm{b}}$ & $1.27 \pm 0.17^{\mathrm{a}}$ & $11.25 \pm 0.61^{\mathrm{b}}$ & $29 \pm 1.2^{\mathrm{b}}$ & $50.47 \pm 3.70^{\mathrm{ab}}$ \\
cv Bologna & $168 \pm 19^{\mathrm{b}}$ & $139 \pm 17^{\mathrm{b}}$ & $27 \pm 2^{\mathrm{a}}$ & $1.15 \pm 0.11^{\mathrm{a}}$ & $9.39 \pm 0.50^{\mathrm{a}}$ & $23 \pm 1.0^{\mathrm{a}}$ & $45.45 \pm 2.21^{\mathrm{a}}$ \\
\hline
\end{tabular}

$W$ dough strength, $P$ tenacity, $L$ extensibility, $P / L$ the tenacity/extensibility ratio; protein amount; total phenolic content and antioxidant activity. Results are expressed as mean \pm standard deviation.

Different letters $(\mathrm{a}-\mathrm{b})$ in the same column correspond to significant differences $(p<0.05)$ 
Acidity, were monitored as commonly used parameters for the characterization of sourdough. Results are reported in Table S1.

Among the doughs, the lowest final volume was recorded in sourdough bread made with Andriolo and Bologna flour, even if they were not statistically different from the other samples, except for the BYA, which displayed the highest final volume, although Andriolo flour technological aptitude was not regarded as optimal for bread-making. As regard to yeast concentrations, all of the BY samples showed a higher cell densities compared to the other two production processes (biga and sourdough), regardless of the type of flour. Yeast densities reflects the type the different applied technologies of leavening. Indeed, yeast densities recorded for sourdough showed values that are usually found in this ecosystem, ca. $10^{7} \mathrm{CFU} / \mathrm{g}$ [11], as well as those reported for biga and straight dough. Lactic acid bacteria, and $\mathrm{pH}$ and acidity (TTA) were also determined, they did not differ among the samples, not depending on the flour, and typical for a sourdough bread [13].

\section{Bread technological analyses}

Two-way ANOVA was carried out to investigate the effects of leavening agent, flour, and their interactions on bread technological features (Table S2). Data are shown in Table 3.

As shown in Table $\mathrm{S} 2$, the textural properties of breads were affected by different factors. Crumb hardness was markedly affected by the interactions of flour and leavening agent $(p<0.0001)$. The values increased from baker's yeast (3.57 $\mathrm{N}$ on average) to sourdough $(5.42 \mathrm{~N}$ on average), and to biga (6.79 $\mathrm{N}$ on average) (Table 3$)$, however this trend was observed only with the use of ancient wheat varieties. Indeed, Bologna samples displayed a different behaviour, baker's yeast sample had the highest value $8.66 \pm 0.50 \mathrm{~N}$, followed by sourdough and biga. The leavening agent showed a significant effect on crumb cohesiveness $(\mathrm{p}=0.032)$, a parameters indicating how a product withstands a second deformation relative to its resistance under the first deformation. Cohesiveness ranged from $0.43 \pm 0.03$ of the $\mathrm{BiB}$ to $0.54 \pm 0.07$ of the BYB. The third considered textural parameter was the springiness, indicating the degree of recovery of the deformed bread to its initial state during the first compression. Both leavening agent and flour influenced this feature $(p=0.033)$, BYV exhibited the highest value among the samples, $0.75 \pm 0.06 \mathrm{~mm}$. As for hardness, the interaction of the factors was highly significant in determining crumb grain characteristics in terms of number of pores/ $\mathrm{cm}^{2}(p=0.0008)$. BYB was characterized by the highest number of pores $/ \mathrm{cm}^{2}, 71.95 \pm 4.23$, not statistically different from the sourdough samples, 66.17 on average. On the opposite, BYA exhibited the lowest value. Leavening agent slightly affected the percentage of pores $(p=0.0032)$, this was particularly highlighted in the Andriolo breads, where sourdough sample value was lower compared to BY one. Loaf height was correlated to the interaction of flour and leavening agent $(p<0.0001)$. As for hardness and crumb grain features, Bologna samples exhibited a different behaviour, especially for the Bi and the BY samples. Loaf height of BYB bread was statistically lower compared to the others BY samples, $4.29 \pm 0.22 \mathrm{~cm}, 5.09 \pm 0.22 \mathrm{~cm}$, and $4.86 \pm 0.17 \mathrm{~cm}$, respectively. Whereas, the $\mathrm{BiB}$ showed the highest value among all the breads, $5.19 \pm 0.35 \mathrm{~cm}$.

Table 3 Bread technological analyses

\begin{tabular}{|c|c|c|c|c|c|c|c|c|c|}
\hline & BYA & $\mathrm{BiA}$ & SDA & BYB & $\mathrm{BiB}$ & SDB & BYV & $\mathrm{BiV}$ & SDV \\
\hline $\begin{array}{l}\text { Hardness } \\
\text { (N) }\end{array}$ & $3.54 \pm 0.60^{\mathrm{a}}$ & $6.64 \pm 1.78^{\mathrm{cde}}$ & $5.09 \pm 0.28^{\mathrm{bc}}$ & $8.66 \pm 0.50^{\mathrm{e}}$ & $4.61 \pm 0.81^{\mathrm{ab}}$ & $7.37 \pm 1.04^{\mathrm{de}}$ & $3.58 \pm 0.72^{\mathrm{a}}$ & $6.94 \pm 1.38^{\text {cde }}$ & $5.75 \pm 1.23^{\mathrm{bcd}}$ \\
\hline $\begin{array}{l}\text { Cohesive- } \\
\text { ness }\end{array}$ & $0.48 \pm 0.04^{\mathrm{ab}}$ & $0.47 \pm 0.05^{\mathrm{ab}}$ & $0.46 \pm 0.02^{\mathrm{ab}}$ & $0.54 \pm 0.07^{\mathrm{b}}$ & $0.43 \pm 0.03^{\mathrm{a}}$ & $0.44 \pm 0.03^{a b}$ & $0.49 \pm 0.08^{\mathrm{ab}}$ & $0.48 \pm 0.05^{\mathrm{ab}}$ & $0.49 \pm 0.06^{\mathrm{ab}}$ \\
\hline $\begin{array}{c}\text { Springi- } \\
\text { ness } \\
(\mathrm{mm})\end{array}$ & $0.67 \pm 0.04^{\mathrm{ab}}$ & $0.66 \pm 0.05^{\mathrm{a}}$ & $0.66 \pm 0.04^{\mathrm{a}}$ & $0.74 \pm 0.05^{\mathrm{ab}}$ & $0.67 \pm 0.03^{\mathrm{ab}}$ & $0.69 \pm 0.04^{\mathrm{ab}}$ & $0.75 \pm 0.06^{\mathrm{b}}$ & $0.68 \pm 0.05^{\mathrm{ab}}$ & $0.66 \pm 0.04^{\mathrm{a}}$ \\
\hline$\%$ pores & $32.00 \pm 1.70^{\mathrm{b}}$ & $31.76 \pm 1.55^{\mathrm{ab}}$ & $27.87 \pm 2.96^{\mathrm{a}}$ & $31.76 \pm 2.29^{\mathrm{ab}}$ & $30.93 \pm 2.83^{\mathrm{ab}}$ & $30.77 \pm 0.93^{\mathrm{ab}}$ & $30.93 \pm 3.31^{\mathrm{ab}}$ & $32.16 \pm 2.78^{b}$ & $29.47 \pm 2.56^{\mathrm{ab}}$ \\
\hline $\begin{array}{l}\text { Numbers } \\
\text { of } \\
\text { pores/ } \\
\mathrm{cm}^{2}\end{array}$ & $54.38 \pm 2.00^{\mathrm{a}}$ & $54.79 \pm 6.98^{\mathrm{ab}}$ & $63.58 \pm 3.11^{\mathrm{cd}}$ & $71.95 \pm 4.23^{\mathrm{e}}$ & $63.04 \pm 3.06^{\mathrm{c}}$ & $70.42 \pm 2.91^{\mathrm{de}}$ & $55.59 \pm 3.78^{\mathrm{ab}}$ & $61.38 \pm 4.17^{\mathrm{bc}}$ & $64.52 \pm 5.99^{\mathrm{cd}}$ \\
\hline $\begin{array}{l}\text { Loaf } \\
\text { height } \\
(\mathrm{cm})\end{array}$ & $5.09 \pm 0.22^{\mathrm{cd}}$ & $4.79 \pm 0.24^{\mathrm{bcd}}$ & $4.51 \pm 0.26^{\mathrm{ab}}$ & $4.29 \pm 0.22^{\mathrm{a}}$ & $5.19 \pm 0.35^{\mathrm{d}}$ & $4.72 \pm 0.23^{\mathrm{bc}}$ & $4.86 \pm 0.17^{\mathrm{bcd}}$ & $4.83 \pm 0.30^{\mathrm{bcd}}$ & $4.48 \pm 0.23^{\mathrm{ab}}$ \\
\hline
\end{tabular}

Texture profile analysis (TPA) parameters: hardness, cohesiveness and springiness; image analysis parameters: $\%$ pores, numbers of pores $/ \mathrm{cm}^{2}$, loaf height. $B Y$ bread obtained with the use of baker's yeast, $B i$ bread obtained with the use of biga, $S D$ bread obtained with the use of sourdough. A: wheat flour cv Andriolo; B: wheat flour cv Bologna; V: wheat flour cv Verna

Different letters in the same row indicate statistically significant differences $(p<0.05)$ 


\section{Bread chemical and nutritional properties}

Two-way ANOVA was carried out to investigate the effects of leavening agent, flour, and their interactions on bread chemical features (Table S2). Data are reported in Table 4.

The differences observed among the flours for total phenolic content and antioxidant activity were not observed in bread, these two features were not affected by none of the factors (Table S2). Probably, the whole production process levelled the differences, thus ancient and modern grain final products were not discriminated based on these characteristics as reported by Valli et al. [26].

Moreover, the total and protein digestibility were significantly affected by leavening agent $(p=0.0002$ and $p=0.048$, respectively). Protein digestibility of sourdough samples was the highest, up to $87.3 \%$. The biga samples ranged from 74.2 to $83.9 \%$, while BY breads did not exceed $81.9 \%$. The enhanced protein digestibility might be attributed to the proteolysis by LAB and to the inactivation of some antinutritional factors such as trypsin inhibitor [27]. Furthermore, acidification by lactic acid bacteria and the resulting reduction of disulfide bonds in gluten proteins are known to increase the solubility of gluten proteins and activation of flour indigenous enzymes, hence making them more susceptible for proteolytic degradation [27].

\section{Bread microbial shelf-life}

Bread microbial shelf-life, determined as mould appearance on bread surface during storage, was also evaluated (Fig. 2). The leavening agent strongly influenced this feature $(p<0.001)$ (Table $\mathrm{S} 2)$. As expected, the acidification of sourdough bread by LAB fermentation slowed moulds development, extending their shelf-life. Indeed, all the sourdough breads showed a shelf-life longer than 13 days, whereas BY and Bi samples did not exceed 10 days.

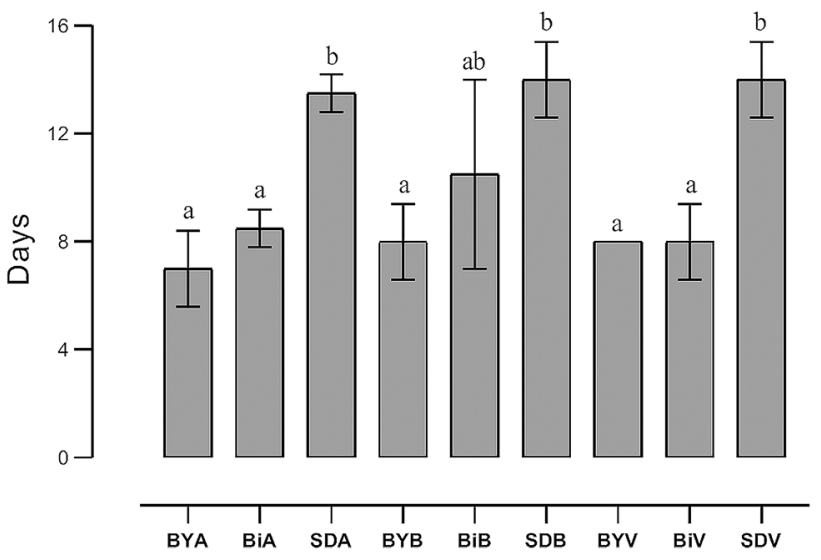

Fig. 2 Bread microbial shelf-life. $B Y$ bread obtained with the use of baker's yeast, $B i$ bread obtained with the use of biga, $S D$ bread obtained with the use of sourdough. A: wheat flour cv Andriolo; B: wheat flour cv Bologna; V: wheat flour cv Verna. Different letters indicate statistically significant differences

\section{Principle component analysis}

A principle component analysis (PCA) was performed to visualize and highlight similarities and variations among the samples (Fig. 3). The variables that were not affected by any factors or interaction (total phenolic compounds and antioxidant activity) in the two-way ANOVA were not included in the PCA. Figure 3a shows the distribution of the samples in the first two principal component for the considered variables, while in Fig. $3 \mathrm{~b}$ the score plot, indicating the influence of the variables in the factor plane, is shown.

The first component (PC1) explains approximately the $42 \%$ of the total variance, whereas the second component (PC2) describes the $29 \%$ of the variance. The PCA showed a noticeable effect of the leavening agent: sourdough samples (made from each of the three whole grain flours), biga

Table 4 Bread chemical and nutritional analyses

\begin{tabular}{|c|c|c|c|c|c|c|c|c|c|}
\hline & BYA & $\mathrm{BiA}$ & SDA & BYB & $\mathrm{BiB}$ & SDB & BYV & $\mathrm{BiV}$ & SDV \\
\hline $\begin{array}{l}\text { Total phenolic } \\
\text { content (mg } \\
\text { GAE/100 g } \\
\text { dwb) }\end{array}$ & $26.10 \pm 5.52^{\mathrm{a}}$ & $25.29 \pm 1.83^{\mathrm{a}}$ & $21.65 \pm 0.60^{\mathrm{a}}$ & $22.26 \pm 0.06^{\mathrm{a}}$ & $22.42 \pm 2.91^{\mathrm{a}}$ & $21.01 \pm 0.19^{\mathrm{a}}$ & $22.63 \pm 0.96^{\mathrm{a}}$ & $22.96 \pm 2.03^{\mathrm{a}}$ & $22.97 \pm 3.82^{\mathrm{a}}$ \\
\hline $\begin{array}{l}\text { Antioxidant } \\
\text { activity (\%) }\end{array}$ & $50.10 \pm 15.30^{\mathrm{a}}$ & $52.16 \pm 9.48^{a}$ & $37.01 \pm 6.32^{\mathrm{a}}$ & $37.53 \pm 4.35^{\mathrm{a}}$ & $40.16 \pm 10.64^{\mathrm{a}}$ & $29.22 \pm 2.81^{\mathrm{a}}$ & $42.25 \pm 9.59^{\mathrm{a}}$ & $44.72 \pm 10.71^{\mathrm{a}}$ & $34.94 \pm 8.15^{\mathrm{a}}$ \\
\hline $\begin{array}{l}\text { Total Digest- } \\
\text { ibility (IVTD } \\
\%)\end{array}$ & $78.00 \pm 3.54^{\mathrm{ab}}$ & $78.75 \pm 2.76^{\mathrm{ab}}$ & $82.55 \pm 3.18^{\mathrm{ab}}$ & $81.40 \pm 1.56^{\mathrm{ab}}$ & $77.00 \pm 11.88^{\mathrm{ab}}$ & $83.90 \pm 9.33^{b}$ & $83.45 \pm 2.19^{\mathrm{ab}}$ & $75.55 \pm 2.76^{\mathrm{a}}$ & $84.05 \pm 4.88^{b}$ \\
\hline $\begin{array}{l}\text { Protein } \\
\text { Digestibility } \\
\text { (PD120\%) }\end{array}$ & $73.86 \pm 5.37^{\mathrm{a}}$ & $75.53 \pm 13.27^{\mathrm{a}}$ & $82.79 \pm 14.26^{\mathrm{a}}$ & $81.78 \pm 0.6^{\mathrm{a}}$ & $83.92 \pm 12.79^{a}$ & $87.28 \pm 17.00^{\mathrm{a}}$ & $77.99 \pm 5.49^{\mathrm{a}}$ & $74.22 \pm 2.45^{\mathrm{a}}$ & $81.18 \pm 18.29^{a}$ \\
\hline
\end{tabular}

$B Y$ bread obtained with the use of baker's yeast, $B i$ bread obtained with the use of $b i g a, S D$ bread obtained with the use of sourdough. A: wheat flour cv Andriolo; B: wheat flour cv Bologna; V: wheat flour cv Verna

Different letters in the same row indicate statistically significant differences $(p<0.05)$ 


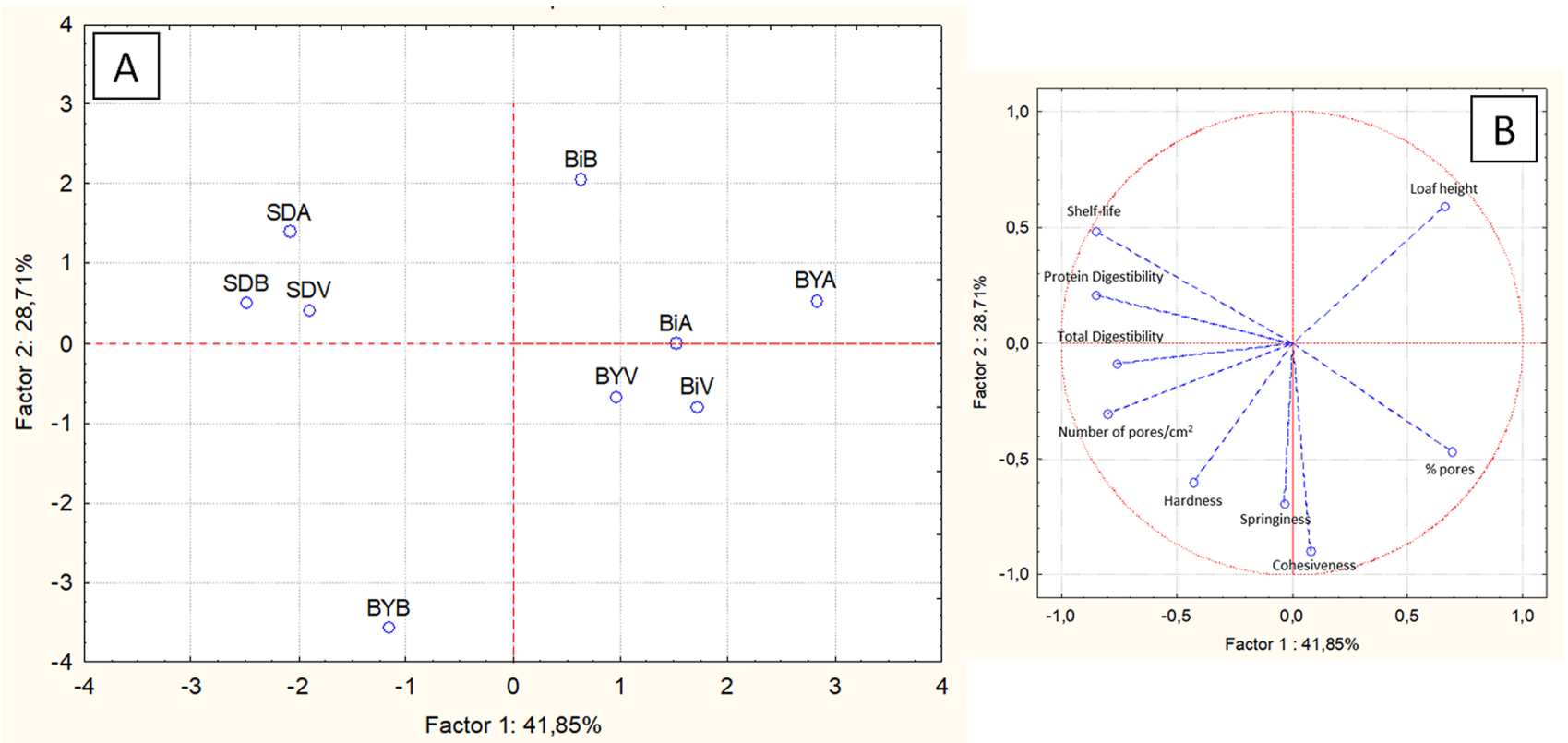

Fig. 3 Principal Component Analysis (PCA): Score plot a: projection of the samples on the factor-plane; Loading plot $\mathbf{b}$ : projection of the variables on the factor-plane. $B Y$ bread obtained with the use of bak-

and baker's yeast samples (only made with the old varieties) formed two clusters. The clustering of sourdough samples depends mostly on the digestibility, the shelf-life, and the number of pores $/ \mathrm{cm}^{2}$. These parameters discriminate along the first component, with a correlation of more than 0.75. Crumb grain characteristics in terms of percentage of pores and loaf height exhibited a good correlation, 0.69 and 0.66 , respectively. The higher $\mathrm{W}$ of flour generally leads to a better gas retention capacity of the dough during the leavening and the baking, allowing the development of a more porous structure. Our findings highlighted a marked effect of the leavening agent, however the influence of the leavening method is not still well established; some works reported that the use of sourdough over $20 \%$ allows the formation of a denser crumb structure and a higher number of pores $/ \mathrm{cm}^{2}$ [28]. The TPA analysis (hardness, cohesiveness, and springiness) and the loaf height differentiated mainly the samples along the second component. These features affected especially the BYB and BiB distribution, which displayed different characteristics compared to the respective with ancient wheat cultivar, leading to a placing outside the two clusters. BiB bread showed the highest loaf height among the samples (Table 3). Crumb hardness and cohesiveness were lower in the BiB sample compared to BYB. Interestingly, sample distribution on the plane pointed out that the use of sourdough reduced the variability due to the flour; indeed, bread made with ancient grains flours showed a similar behaviour regardless of the leavening agent. In this connection, in a work by Guerrini et al. [29], a survey on the er's yeast, $B i$ bread obtained with the use of biga, $S D$ bread obtained with the use of sourdough. A: wheat flour cv Andriolo; B: wheat flour cv Bologna; V: wheat flour cv Verna

technology employed when whole and ancient grains are used highlighted that most of the producers uses the sourdough technique. This technique is general recognized more suitable for bread-making with ancient grains, increasing their workability as well as the final product quality [21].

\section{Crumb grain characteristics}

Digital image analysis was carried out to determine crumb grain characteristics of the different bread types. Images of bread slices are shown in Fig. S1.

Pores were divided into five classes based on their equivalent diameters, and their relative area fraction was calculated (Fig. 4).

Crumb grain measurements highlighted significant differences in the bread crumb related to the leavening agent and to flour. Sourdough breads showed the highest area percentage (ca $41 \%)$ of pores with the small diameter $(<0.20 \mathrm{~cm})$. Small holes or voids in the crumb contribute to texture, eating quality, mechanical strength, and perceived product freshness [28]. The higher percentage of biggest pores, corresponding to an equivalent diameter $>0.5 \mathrm{~cm}$, were found in the bread leavened with baker's yeast and biga in all the cultivar, with some exceptions depending on the flour. BiA exhibited the higher percentage, up to $23.80 \%$, and apart from $\mathrm{BiB}(13 \%)$, the others were in the range of 18-19. In sourdough breads this percentage did not exceed the $11 \%$ in samples made from Bologna and Verna varieties, while in SDA was $17 \%$. Results indicated a marked effect of the 
Fig. 4 Pore area percentage distribution based on the equivalent diameter dimension of pores. Class 1 : $0.05<$ eq.d. $\leq 0.1 \mathrm{~cm}$; class 2 : $0.1<$ eq.d. $\leq 0.2 \mathrm{~cm}$; class 3 : $0.2<$ eq.d. $\leq 0.3 \mathrm{~cm}$; class 4 : $0.3<$ eq.d. $\leq 0.5 \mathrm{~cm}$; class 5 : eq.d. $>0.5 \mathrm{~cm}$

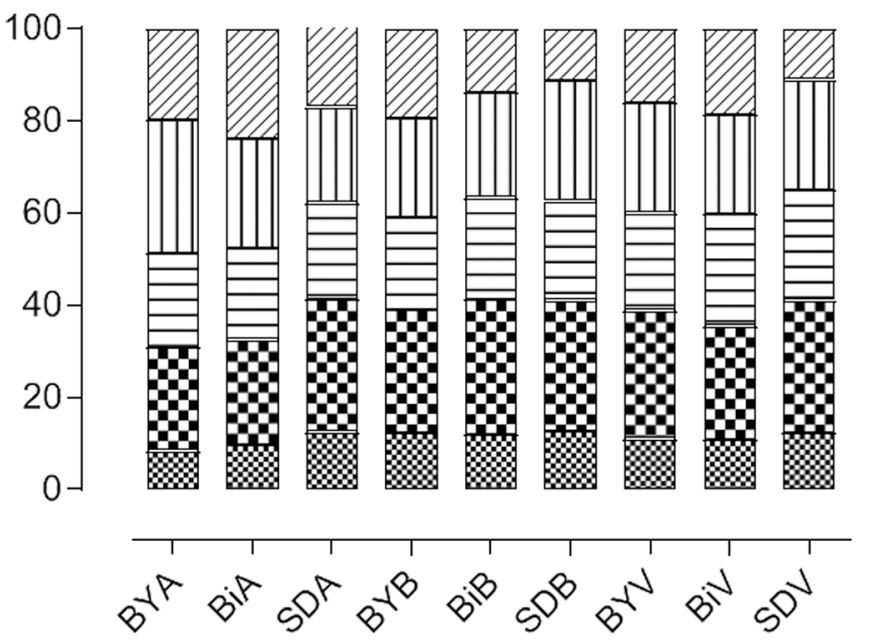

एus eq.d. $>0.50$

पाل $0.30<$ eq.d. $\leq 0.50$

$0.20<$ eq. $d . \leq 0.30$

$0.10<$ eq.. . $\leq 0.20$

$0.05<$ eq.d. $\leq 0.10$ leavening agent, with some minor differences due to the flour variety.

\section{Conclusions}

In this work, we evaluated the influence of the leavening agent (baker's yeast, biga, and sourdough) on several bread technological and nutritional characteristics of breads made with soft wheat whole flour (two ancient varieties, Andriolo and Verna, and a modern grain variety, Bologna). Ancient grain flours were characterized by similar rheological parameters, which, however, were not optimal for bread-making. Technological and nutritional analyses were performed for characterizing breads, and two-way ANOVA allowed determining which of them was affected by the leavening agent and/or flour. The following principle component analysis showed sample distribution and dependence from the selected variables. Particularly, protein digestibility, crumb grain characteristics and microbial shelf-life led to the main differences among the samples. Ancient wheat flour breads were similar when the same leavening agent was used. The use of sourdough had a sharp effect, levelling the potential differences due to flour, and leading to bread with similar characteristics to samples from a modern cultivar. The combination of technological and nutritional analysis supplied an insight on the bread quality dependence on production process, thus providing indications especially for ancient wheat flours utilization.

Supplementary Information The online version contains supplementary material available at https://doi.org/10.1007/s00217-021-03740-y.

Author contributions MV: conceptualization, formal analysis, investigation, roles/writing — original draft, writing—review and editing. VG: conceptualization, investigation, roles/writing—original draft. Niccolò Pini: investigation. SG: writing-review and editing. CS: investigation, formal analysis, writing — review and editing. Lisa Granchi: supervision; writing-review and editing.

Funding Open access funding provided by Università degli Studi di Firenze within the CRUI-CARE Agreement. This research did not receive any specific Grant from funding agencies in the public, commercial, or not-for-profit sectors.

\section{Declarations}

Conflict of interest None.

Compliance with ethics requirements This study does not contain any studies with human participants or animals performed by any of the authors.

Open Access This article is licensed under a Creative Commons Attribution 4.0 International License, which permits use, sharing, adaptation, distribution and reproduction in any medium or format, as long as you give appropriate credit to the original author(s) and the source, provide a link to the Creative Commons licence, and indicate if changes were made. The images or other third party material in this article are included in the article's Creative Commons licence, unless indicated otherwise in a credit line to the material. If material is not included in the article's Creative Commons licence and your intended use is not permitted by statutory regulation or exceeds the permitted use, you will need to obtain permission directly from the copyright holder. To view a copy of this licence, visit http://creativecommons.org/licenses/by/4.0/.

\section{References}

1. Gómez M, Gutkoski LC, Bravo-Núñez Á (2020) Understanding whole-wheat flour and its effect in breads: a review. Compr Rev Food Sci F 19(6):3241-3265. https://doi.org/10.1111/1541-4337. 12625

2. Liu RH (2007) Whole grain phytochemicals and health. J Cereal Sci 46(3):207-219. https://doi.org/10.1016/j.jcs.2007.06.010

3. Dinu M, Whittaker A, Pagliai G, Benedettelli S, Sofi F (2018) Ancient wheat species and human health: biochemical and clinical 
implications. J Nutr Biochem 52:1-9. https://doi.org/10.1016/j. jnutbio.2017.09.001

4. Pagliai G, Venturi M, Dinu M, Galli V, Colombini B, Giangrandi I, Maggini N, Sofi F, Granchi L (2020) Effect of consumption of ancient grain bread leavened with sourdough or with baker's yeast on cardio-metabolic risk parameters: a dietary intervention trial. Int J Food Sci Nutr. https://doi.org/10.1080/09637486.2020.17999 56

5. Sofi F, Dinu M, Pagliai G, Cei L, Sacchi G, Benedettelli S, Stefani G, Gagliardi E, Tosi P, Bocci R, Bussi B, De Santis G, Rodriguez y Hurtado I, De Kochko P, Riviere P, Carrascosa-García M, Martínez I (2018) Health and nutrition studies related to cereal biodiversity: a participatory multi-actor literature review approach. Nutrients 10(9):1207. https://doi.org/10.3390/nu10091207

6. Dinelli G, Carretero AS, Di Silvestro R, Marotti I, Fu S, Benedettelli S, Ghiselli L, Gutiérrez AF (2009) Determination of phenolic compounds in modern and old varieties of durum wheat using liquid chromatography coupled with time-of-flight mass spectrometry. J Chromatogr A 1216(43):7229-7240. https://doi.org/ 10.1016/j.chroma.2009.08.041

7. Shewry PR, Hey S (2015) Do "ancient" wheat species differ from modern bread wheat in their contents of bioactive components? J Cereal Sci 65:236-243. https://doi.org/10.1016/j.jcs.2015.07.014

8. Cappelli A, Cini E, Guerrini L, Masella P, Angeloni G, Parenti A (2018) Predictive models of the rheological properties and optimal water content in doughs: an application to ancient grain flours with different degrees of refining. J Cereal Sci 83:229-235. https://doi.org/10.1016/j.jcs.2018.09.006

9. Migliorini P, Spagnolo S, Torri L, Arnoulet M, Lazzerini G, Ceccarelli S (2016) Agronomic and quality characteristics of old, modern and mixture wheat varieties and landraces for organic bread chain in diverse environments of northern Italy. Eur J Agron 79:131-141. https://doi.org/10.1016/j.eja.2016.05.011

10. Parenti O, Guerrini L, Cavallini B, Baldi F, Zanoni B (2020) Breadmaking with an old wholewheat flour: optimization of ingredients to improve bread quality. LWT-Food Sci Technol 121:108980. https://doi.org/10.1016/j.lwt.2019.108980

11. Venturi M, Guerrini S, Vincenzini M (2012) Stable and non-competitive association of Saccharomyces cerevisiae, Candida milleri and Lactobacillus sanfranciscensis during manufacture of two traditional sourdough baked goods. Food Microbiol 31(1):107-115. https://doi.org/10.1016/j.fm.2012.02.011

12. Boukid F, Gentilucci V, Vittadini E, De Montis A, Rosta R, Bosi S, Dinelli G, Carini E (2020) Rediscovering bread quality of "old" Italian wheat (Triticum aestivum L. ssp. aestivum) through an integrated approach: physicochemical evaluation and consumers' perception. LWT-Food Sci Technol 122:109043. https://doi.org/ 10.1016/j.lwt.2020.109043

13. Galli V, Venturi M, Pini N, Guerrini S, Granchi L, Vincenzini M (2019) Liquid and firm sourdough fermentation: microbial robustness and interactions during consecutive backsloppings. LWTFood Sci Technol 105:9-15. https://doi.org/10.1016/j.lwt.2019. 02.004

14. Alvarez-Jubete L, Wijngaard H, Arendt EK, Gallagher E (2010) Polyphenol composition and in vitro antioxidant activity of amaranth, quinoa buckwheat and wheat as affected by sprouting and baking. Food Chem 119(2):770-778. https://doi.org/10.1016/j. foodchem.2009.07.032

15. Pasini G, Simonato B, Giannattasio M, Peruffo AD, Curioni A (2001) Modifications of wheat flour proteins during in vitro digestion of bread dough, crumb, and crust: an electrophoretic and immunological study. J Agric Food Chem 49(5):2254-2261. https://doi.org/10.1021/jf0014260

16. Kim S, Kwak HS, Jeong Y (2017) Effect of water roux starter (Tangzhong) on texture and consumer acceptance of rice pan bread. J Texture Stud 48(1):39-46. https://doi.org/10.1111/jtxs. 12204

17. Demirkesen I, Sumnu G, Sahin S (2013) Image analysis of glutenfree breads prepared with chestnut and rice flour and baked in different ovens. Food Bioproc Technol 6(7):1749-1758. https:// doi.org/10.1007/s11947-012-0850-5

18. Barber B, Ortolá C, Barber S, Fernandez F (1992) Storage of packaged white bread. Zeitschrift Lebensmittel-Untersuchung Forschung 194(5):442-449. https://doi.org/10.1007/BF01197726

19. Boukid F, Folloni S, Sforza S, Vittadini E, Prandi B (2017) Current trends in ancient grains-based foodstuffs: insights into nutritional aspects and technological applications. Compr Rev Food Sci F 17(1):123-136. https://doi.org/10.1111/1541-4337.12315

20. Ghiselli L, Rossi E, Whittaker A, Dinelli G, Baglio AP, Andrenelli L, Benedettelli S (2016) Nutritional characteristics of ancient Tuscan varieties of Triticum aestivum L. Ital J Agron 11(4):237-245. https://doi.org/10.4081/ija.2016.750

21. Parenti A, Guerrini L, Granchi L, Venturi M, Benedettelli S, Nistri F (2013) Control of mixing step in the bread production with weak wheat flour and sourdough. J Agric Eng. https://doi.org/10.4081/ jae.2013.307

22. Ficco DBM, Saia S, Beleggia R, Fragasso M, Giovanniello V, De Vita P (2017) Milling overrides cultivar, leavening agent and baking mode on chemical and rheological traits and sensory perception of durum wheat breads. Sci Rep 7(1):1-13. https://doi. org/10.1038/s41598-017-14113-5

23. Van den Broeck HC, de Jong HC, Salentijn EM, Dekking L, Bosch D, Hamer RJ, Gilissen LJWJ, van der Meer IM, Smulders MJ (2010) Presence of celiac disease epitopes in modern and old hexaploid wheat varieties: wheat breeding may have contributed to increased prevalence of celiac disease. Theor Appl Genet 121(8):1527-1539. https://doi.org/10.1007/s00122-010-1408-4

24. Barański M, Lacko-Bartošová M, Rembiałkowska E, LackoBartošová L (2020) The effect of species and cultivation year on phenolic acids content in ancient wheat. Agron 10(5):673. https:// doi.org/10.3390/agronomy10050673

25. Galli V, Venturi M, Guerrini S, Blandino M, Luti S, Pazzagli L, Granchi L (2020) Antioxidant properties of sourdoughs made with whole grain flours of hull-less barley or conventional and pigmented wheat and by selected lactobacilli strains. Foods 9(5):640. https://doi.org/10.3390/foods9050640

26. Valli V, Taccari A, Di Nunzio M, Danesi F, Bordoni A (2018) Health benefits of ancient grains. Comparison among bread made with ancient, heritage and modern grain flours in human cultured cells. Food Res Int 107:206-215. https://doi.org/10.1016/j.foodr es.2018.02.032

27. Gobbetti M, Rizzello CG, Di Cagno R, De Angelis M (2014) How the sourdough may affect the functional features of leavened baked goods. Food Microbiol 37:30-40. https://doi.org/10.1016/j. fm.2013.04.012

28. Crowley P, Schober TJ, Clarke CI, Arendt EK (2002) The effect of storage time on textural and crumb grain characteristics of sourdough wheat bread. Eur Food Res Technol 214(6):489-496. https://doi.org/10.1007/s00217-002-0500-7

29. Guerrini L, Parenti O, Angeloni G, Zanoni B (2019) The bread making process of ancient wheat: a semi-structured interview to bakers. J Cereal Sci 87:9-17. https://doi.org/10.1016/j.jcs.2019. 02.006

Publisher's Note Springer Nature remains neutral with regard to jurisdictional claims in published maps and institutional affiliations. 